\title{
Comunicação
}

[Communication $]$

\section{Células mononucleares da medula óssea no tratamento da ruptura total dos tendões flexores e ligamento suspensor do boleto em equino}

\author{
[Bone marrow mononuclear cells in the treatment of complete tear of flexor tendons and \\ suspensory ligament in the horse] \\ A.L.M. Yamada ${ }^{1}$, P.G.G. Oliveira ${ }^{1}$, A.M. Carvalho ${ }^{1}$, M.J. Watanabe $^{2}$, C.A. Hussni ${ }^{2}$, A.L.G. Alves ${ }^{2}$ \\ ${ }^{1}$ Aluno de pós-graduação - FMVZ-UNESP - Botucatu, SP \\ ${ }^{2}$ FMVZ-UNESP \\ Distrito de Rubião Júnior s/n - Caixa Postal 560 \\ 18618-000 - Botucatu, SP
}

Os tendões flexores do equino são frequentemente agredidos por lesões causadas pela sua utilização suprafisiológica ou por traumas diretos a essas estruturas. Tais traumas podem originar solução de continuidade resultando na ruptura total dos tendões flexor digital superficial (TFDS) e flexor digital profundo (TFDP) ou do ligamento suspensor do boleto (LSB). Lesões lacerativas são graves e resultam, na maioria dos casos, em imediata impotência funcional do membro, com sequelas morfofuncionais, resultante da complexidade reparatória tendoligamentar ou de infecções (O'Sullivan, 2007; Verwilghen et al., 2010). O tratamento das lesões lacerativas dos tendões envolve intervenção cirúrgica e reabilitação póscirúrgica, que consiste na administração de anti-inflamatórios, antibióticos, imobilização, ferrageamento corretivo, fisioterapia e, recentemente, o uso da bioengenharia (Verwilghen et al., 2010).

A fração celular mononuclear, obtida por meio da punção da medula óssea, tem sido amplamente estudada em lesões tendoligamentares de equinos, apresenta fácil separação e pode ser utilizada como um coadjuvante no tratamento de enfermidades tendíneas (Crovace et al., 2010). O aspirado de medula óssea possui importantes componentes que participam do processo de reparação tecidual como fatores de crescimento e células progenitoras (Barreira et al., 2008; Alves et al., 2009; Fortier et al., 2010). O tratamento de lesões tendíneas e ligamentares com frações

Recebido em 30 de maio de 2011

Aceito em 1 de setembro de 2011

E-mail: anamyamada@fmvz.unesp.br mononucleares da medula óssea resulta em reparação de melhor qualidade, por meio da expressão do potencial proliferativo, imunomodulador e quimiotáxico desse material biológico, além de igualmente estimular a síntese da matriz extracelular, liberar citocinas - como os fatores de crescimento - e exercer efeito antiinflamatório (Pacini et al., 2007; Carvalho, 2009; Fortier et al., 2010). Este trabalho refere-se à descrição do caso de uma potra com laceração do TFDS, TFDP e LSB, submetida ao tratamento com a fração mononuclear de medula óssea.

Uma potra, da raça Quarto de Milha, com dois meses de idade, foi encaminhada ao Hospital Veterinário Escola por apresentar lesão com solução de continuidade, lacerativa, de aproximadamente $10 \mathrm{~cm}$ de diâmetro, no terço final do metatarso do membro posterior esquerdo (MPE), resultante de ferimento em arame liso. Ao exame físico local, observaram-se a ruptura traumática total do TFDS, TFDP, LSB e dos plexos laterais vasculonervosos, e grave hiperextensão metatarsofalangeana. A potra foi submetida à anestesia geral inalatória para a sutura e reaproximação dos cotos tendíneos, utilizando-se o padrão de sutura locking-loop com fio vicryl número dois. Após a indução anestésica do animal, a medula óssea na região da $5^{\mathrm{a}}$ esternebra foi puncionada com uma agulha modelo Komiyashiki, 11G. O sangue medular, cerca de seis mililitros, foi diluído em DPBS (Dulbecco's Phosphate Buffered Saline - Sigma Aldrich), filtrado em equipo de transfusão, depositado sobre Histopaque (Histopaque Sigma Aldrich) e levado à centrífuga durante 30 
minutos a 500g. Consequentemente, houve formação do halo mononuclear, que foi separado e lavado repetidamente com DPBS. O implante intralesional foi realizado com as células mononucleares suspensas em $0,5 \mathrm{~mL}$ de plasma do sangue medular autólogo.

O membro foi imobilizado com penso RobertJones e tala de PVC. Ao final de 60 dias de evolução, o penso e a tala de PVC foram completamente retirados e a ferida apresentavase completamente cicatrizada. A potra deixou o Hospital Veterinário apoiando o MPE, com discreta hiperextensão da articulação metatarsofalangeana. Foi sugerido um apoio de madeira igualmente plano, extendido nos talões, medindo $15 \mathrm{~cm}$ de comprimento e fixado ao casco com resina acrílica para auxiliar o apoio do membro. Aos 120 dias de evolução, a potra retornou ao Hospital Veterinário para exame físico e ultrassonográfico. Observou-se, ao exame físico, discreta assimetria da articulação metatarsofalangeana em relação à contralateral. A palpação das estruturas tendo-ligamentares era indolor, passível de identificação isolada do TFDS, TFDP e LSB ao longo do metatarso, porém havia aumento de volume palmar firme (fibrose) exatamente na região da ruptura.

As imagens ultrassonográficas demonstraram completo preenchimento reparatório do TFDS, TFDP e LSB apenas por fibrose ainda desorganizada e bem vascularizada na região da ruptura (2B/3A). Os tendões flexores, principalmente o TFDS, encontravam-se moderadamente hipoecoicos em toda a extensão. As bainhas tendíneas e o ligamento palmar estavam espessados, havia acúmulo de líquido e aderências principalmente na altura da lesão. A falha tendínea e ligamentar consequente da laceração foi totalmente preenchida. $\mathrm{O}$ animal recebeu alta com 120 dias de tratamento. Recomendaram-se caminhadas ao passo com duração de 20 minutos, duas vezes ao dia, seguida de massagem nas estruturas tendoligamentares com diclofenaco dietilamônio gel e dimetilsulfóxido gel, seguido de liga de algodão.

O sucesso e a rapidez do processo de reparação da lesão tendínea no caso descrito foram consequentes da interação entre a estrutura de suporte sobre o qual ocorreu o processo de reparação decorrente da manipulação cirúrgica e pós-cirúrgica, fatores de crescimento e uma população de células (Koch et al., 2009). A reparação desse tipo de lesão tendínea em geral é extremamente lenta e apresenta, quase na totalidade, a formação de uma cicatriz fibrosa, rica em colágeno tipo III. Essa fibrose formada é significativamente menos funcional que o tecido tendíneo original, além de apresentar menor capacidade tênsil. Animais que apresentam a ruptura total dos tendões flexores, como no caso relatado, são submetidos a tratamentos laboriosos e demorados, com processo de reabilitação extenso, apresentando, mesmo assim, uma cicatrização tendínea desorganizada, com grande quantidade de fibrose, grande probabilidade de recidiva, claudicação intermitente e, muitas vezes, deficiências posturais (O'Sullivan, 2007; Verwilghen, et al. 2010). Para contornar tais problemas, optou-se pela utilização da bioengenharia, com a fração mononuclear de medula óssea.

As células foram obtidas de tecido adulto, o que possibilitou o implante autólogo, diminuiu o risco de rejeição do material decorrente de resposta imune e permitiu o provimento dos diversos fatores biológicos presentes na fração medular. $\mathrm{O}$ aspirado integral de medula óssea pode ser transfundido para o receptor sem processamento adicional (Barreira et al., 2008) ou após a separação da fração mononuclear (Carvalho, 2009). A fração mononuclear possui um número menor de células-tronco quando comparada às células mesenquimais cultivadas e expandidas (Carvalho, 2009; Koch et al., 2009). Porém, a fração mononuclear possui integrantes importantes no processo de reparação tecidual como fatores de crescimento, que são anabólicos e favorecem a vascularização e as células mononucleares, inclusive as mesenquimais, que possibilitam a melhor organização da microestrutura tendínea por meio da síntese da matriz extracelular, melhor organização das fibras de colágeno, reparação precoce e possuem grande ação mitogênica e proliferativa. $\mathrm{O}$ aspirado medular também possui efeito antiinflamatório, apresenta fácil preparação, manipulação e baixo custo, podendo ser rotineiramente utilizado como adjuvante em casos semelhantes, apresentando resultado favorável no processo de reparação (Barreira et al., 2008; Lacitignola et al., 2008; Alves et al., 2009; Carvalho, 2009; Fortier et al., 2010). 


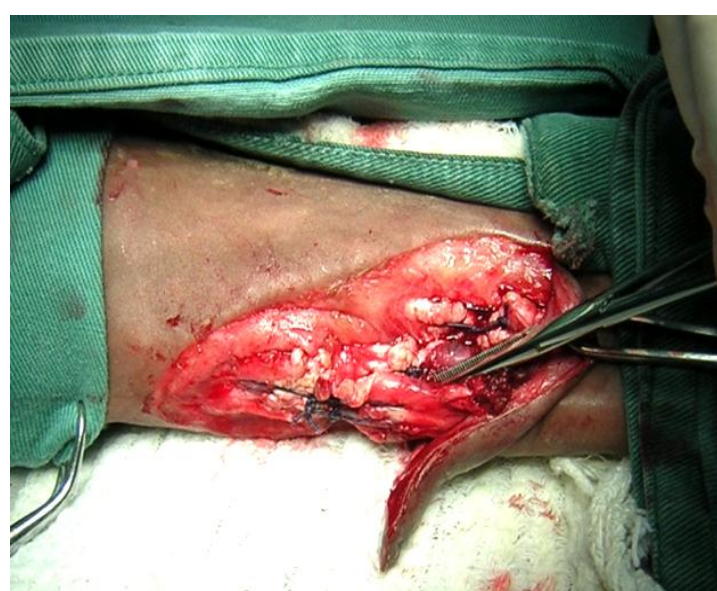

Figura 1. Equino. Sutura dos cotos tendíneos com o padrão "locking-loop".

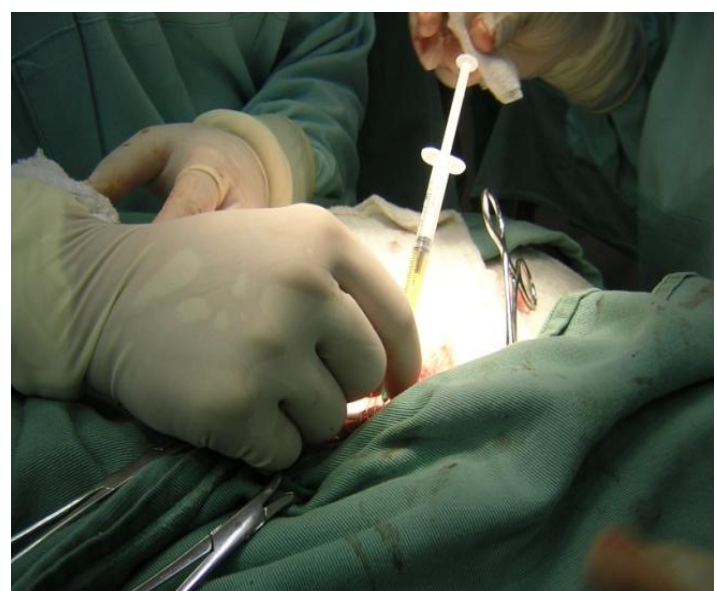

Figura 2. Equino. Aspecto da suspensão intralesional de células mononucleares.

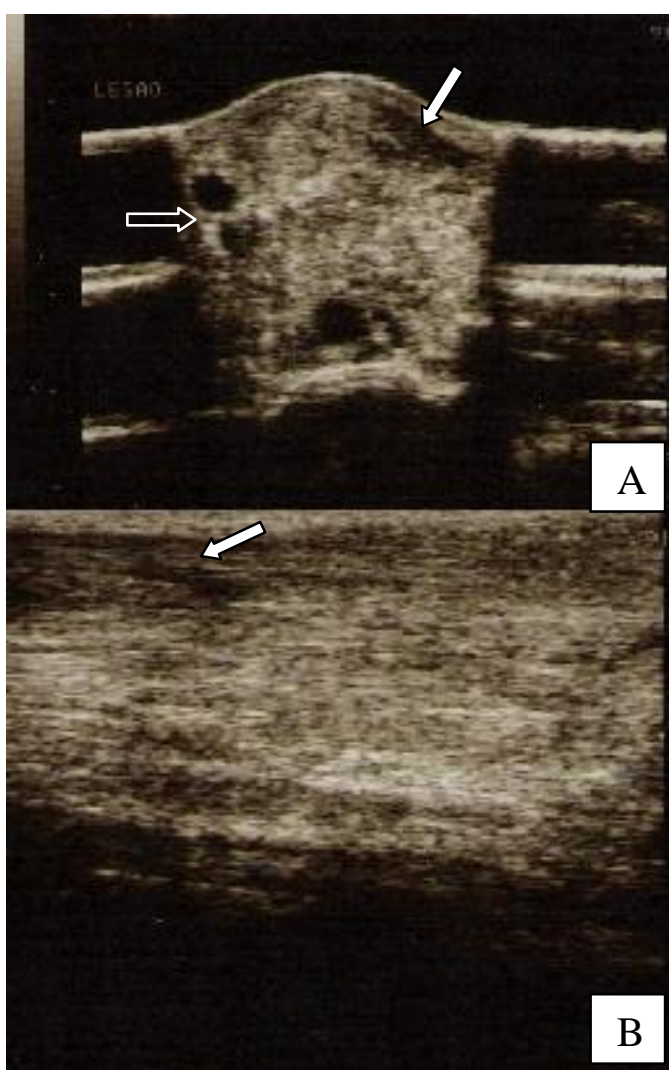

Figura 3. Equino. Imagem ultrassonográfica nos cortes transversal (A) e longitudinal (B) na região da lesão (2B/3A) aos 120 dias de evolução. Observa-se o preenchimento amorfo cicatricial. A seta cheia destaca lesões. As setas vazias destacam neovasos.

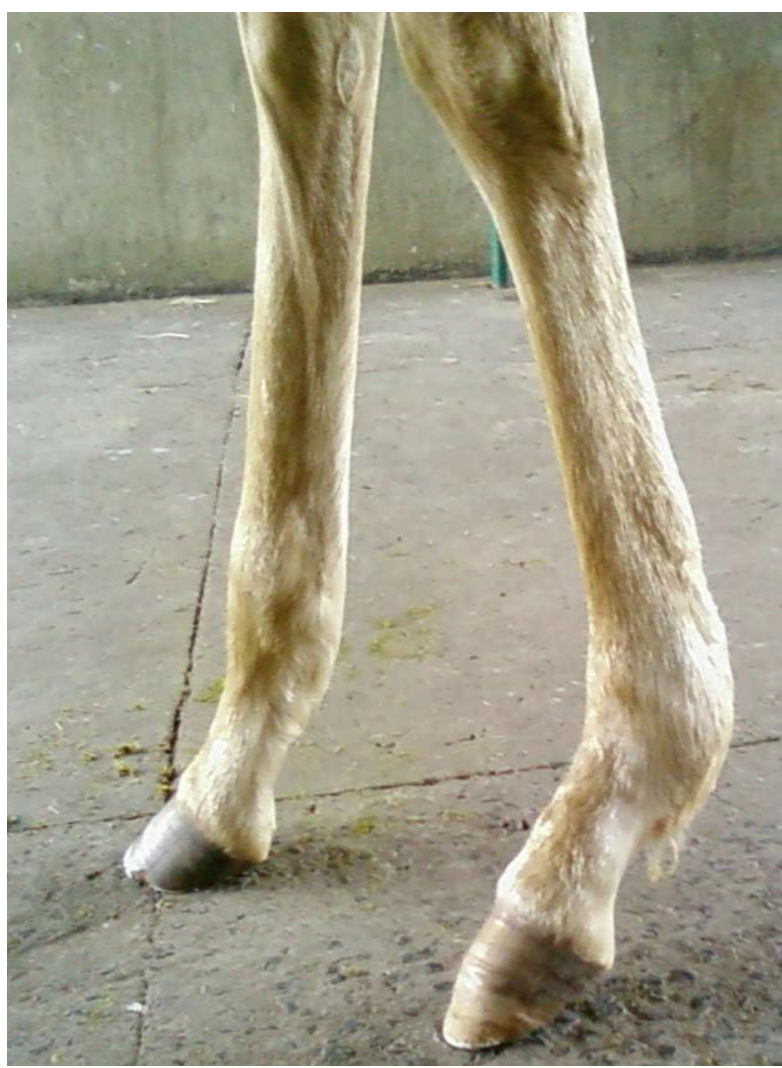

Figura 4. Equino. Imagem da potra as 120 dias de evolução. Observa-se leve hiperextensão da articulação metacarpofalangeana do MPE. 
No presente caso, foi observada rápida desinflamação e grande neovascularização local na fase inicial, o que é desejável, pois acresce o processo reparatório. As imagens ultrassonográficas demonstraram rápida diminuição da efusão local e bom preenchimento tecidual até 120 dias de evolução. Ao final, observou-se que a associação dos tratamentos convencionais com a fração mononuclear de medula óssea proporcionou reparação de melhor qualidade quando comparada a tratamentos convencionais habitualmente utilizados no Hospital Veterinário Escola. Houve significativa redução da hiperextensão da articulação metacarpofalangeana, imagens ultrassonográficas que demonstraram preenchimento celular aquém do tempo esperado e rápido decréscimo da inflamação. A instituição da fisioterapia, abordada pelos exercícios controlados, e a tendinite crônica residual, tratada de forma convencional, completam a abordagem terapêutica, refletindo em um melhor prognóstico para o animal.

Palavras-chave: equino, tendão, tratamento, lesão, mononuclear

\section{ABSTRACT}

This paper describes the case of a horse treated in a Teaching Veterinary Hospital. The sutures of the flexor apparatus associated with cell therapy, the stem cell, provided a rapid response of repair compared to other cases treated in routine of the Hospital. The association of conventional treatments with the mononuclear fraction of bone marrow significantly contributed to the reduction of the hyperextension of the metatarsophalangeal joint. Ultrasound images showed rapid fill cell and decrease in inflammation.

Keywords: equine, tendon, treatment, injury, mononuclear

\section{REFERÊNCIAS BIBLIOGRÁFICAS}

ALVES, A.L.G.; VIEIRA, M.E.M.; BARREIRA, A.P.B. et al. Protocolo de isolamento de células mononucleares de medula óssea de equinos. Rev. Vet Zootec., v.16, p.650-655, 2009.

BARREIRA, A.P.B.; ALVES, A.L.G.; SAITO, M.E. et al. Autologous implant of bone marrow mononuclear cells as treatment of induced equine tendinitis. Intern. J. Appl. Res. Vet. Med., v.6, p.46-54, 2008

CARVALHO, A. M. Implante autólogo de célulastronco mesenquimais do tecido adiposo no tratamento de tendinites experimentais em equinos: avaliação clínica, ultrassonográfica, histopatológica e imunoistoquímica. 2009. 134f. Dissertação (Mestrado), Faculdade de Medicina Veterinária e Zootecnia, Universidade Estadual Paulista, Botucatu, SP.

CROVACE, A.; LACITIGNOLA, L.; ROSSI, G. et al. Histological and immunohistochemical evaluation of autologous cultured bone marrow mesenchymal stem cells and bone marrow mononucleated cells in collagenase-induced tendinitis of equine superficial digital flexor tendon. Vet. Med. Int., v.2010, 2010 doi:10.4061/2010/250978.

FORTIER, L.; POTTER H.G.; RICKEY, E.J. et al. Concentrated bone marrow aspirate improves fullthickness cartilage repair compared with microfracture in equine model. J. Bone Jt. Surg., v.92, p.1927-1937, 2010.
KOCH, T.G.; BERG, L.C.; BETTS, D.H. Current and future regenerative medicine - Principles, concepts, and therapeutic use of stem cell therapy and tissue engineering in equine medicine. Can. Vet. J., v.50, p.155-165, 2009.

LACITIGNOLA, L.; CROVACE, A.; ROSSI, G. et al. Cell therapy for tendinitis, experimental and clinical report. Vet. Res. Commun., v.32, p.33-38, 2008.

O'SULLIVAN, C.B. Injuries of the flexor tendons: focus on the superficial digital flexor tendon. Clin. Tech. Equine Pract., v.6, p.189-197, 2007.

PACINI, S.; SPINABELLA, S.; TROMBI, L. et al. Suspension of bone marrow-derived undifferentiated mesenchymal stromal cells for repair of superficial digital flexor tendon in race horses. Tissue Engin., v.13, p.2949-2955, 2007.

VERWILGHEN, D.; CAUDRON, I.; VAN GALEN G. et al. Les tendinopathies et desmopathies de la région métacarpienne et tarsienne: une revue des thérapies actuelles Seconde partie: les traitements. Ann. Med. Vet., v.154, p.1-15, 2010. 